\title{
La resolución de los conflictos territoriales: reflexiones desde un constitucionalismo global $^{1}$
}

\section{The resolution of territorial disputes: reflections from a global constitutionalism}

\author{
M. ${ }^{a}$ Nieves Alonso García, \\ Universidad de León \\ malong@unileon.es \\ Tamara Álvarez Robles \\ Universidad de León \\ talvr@unileon.es
}

\begin{abstract}
RESUMEN
La habilitación de fórmulas que contribuyan a reducir cuantitativamente y mitigar cualitativamente la virulencia de los conflictos de carácter territorial, en particular en la España autonómica, es un reto continuo que se ha afrontado desde distintas perspectivas. La ahora desarrollada se centrará en explorar las posibilidades que pueden derivarse de las estrategias compartidas por actuaciones de mediación, arbitraje o conciliación.

El trabajo rastrea, desde una referencia al constitucionalismo global, la esencia y peculiaridad de los conflictos territoriales, la peculiaridad de los conflictos territoriales y las posibilidades a explorar para su solución con carácter previo a la judicialización de los mismos.

Una mención especial se referenciará a las experiencias de apertura directa a los ciudadanos de canales de participación integrados en los mecanismos negociadores y decisorios.
\end{abstract}

\section{PALABRAS CLAVE}

Conflictos territoriales, mediación, arbitraje, conciliación, convenciones territoriales.

\begin{abstract}
Enabling formulas that help to reduce quantitatively, qualitatively and to mitigate the virulence of conflicts of territorial nature, particularly in the autonomous Spain, is the aim of this paper. It will focus on exploring the possibilities that can result from mediation, arbitration, conciliation and strategies that encourage direct participation of citizens in public affairs. The framework is linked to global constitutionalism: the base of the transferability of results from private to public and from international to state levels. The essence of the conflict, territorial conflicts, and the main contributions of mediation and arbitration in the field of territorial disputes will be the essence. A special mention will refer the experiences of citizen's direct participation as channels integrated into the negotiating and decision-making mechanisms in democratic and constitutional States.
\end{abstract}

\section{KEYWORDS}

Territorial disputes, mediation, arbitration and territorial conventions.

1 Este trabajo se enmarca en el proyecto «Nuevas estrategias participativas para la resolución prejudicial de conflictos en los Estados compuestos. Estudio comparado Canadá, Estados Unidos y España», financiado por el INAP, convocatoria 2016. En su redacción han colaborado, además de las autoras mencionadas, todos los miembros del equipo. 


\section{SUMARIO}

1. INTRODUCCIÓN. 2. UN CONTEXTO CONSTITUCIONAL GLOBAL. 3. CONFLICTOS: SUS DENOMINADORES COMUNES. 3.1. PRINCIPIOS DE «SOLUCIÓN PACÍFICA DE LOS CONFLICTOS» Y DE «LIBRE ELECCIÓN DE MEDIOS». 3.2. SISTEMAS DE RESOLUCIÓN DE CONFLICTOS COMO REFERENTE GLOBAL. A) Negociación. B) Investigación. C) Mediación. D) Conciliación. E) Arbitraje. F) Convención constitucional: la vía de la participación ciudadana. 4. CONFLICTOS TERRITORIALES. 4.1. EL DENOMINADOR COMÚN DE LOS CONFLICTOS TERRITORIALES A TENOR DE LOS SUPUESTOS PRÁCTICOS: QUEBEC, PAÍS VASCO Y CATALUÑA. 3.2. DEFINICIÓN, VÍAS DE RESOLUCIÓN Y SUS CARACTERÍSTICAS. REFLEXIONES FINALES. REFERENCIAS BIBLIOGRÁFICAS. REFERENCIAS DOCUMENTALES.

\section{INTRODUCCIÓN}

La habituación a los conflictos territoriales y a los mecanismos judiciales con los que se aborda su resolución son la reflexión inicial de la que parte este trabajo. Una resignación frente a una «hiperconflictividad» ante el Tribunal Constitucional y el éxito relativo de procedimientos como el diseñado por el art. $33.2^{2}$ LOTC insta a la incorporación de otros cauces que se conciben necesariamente como ancilares de los ya mencionados (STC 13/1992, FJ 7).

La contextualización en un marco global de muchos conflictos territoriales, tanto interestatales, como intraestatales, va a ser el punto de partida de una propuesta formulada con una estructura a modo de silogismo. La primera proposición de este argumento hace referencia a los nexos que unen conflictos de origen y/o manifestación territorial y que se han prodigado a lo largo de la historia y la geografía. Estas se subsumen en el planteamiento formulado desde el constitucionalismo global. El segundo argumento se centrará en mecanismos de resolución de conflictos de carácter prejudicial, en particular la conciliación, la mediación, el arbitraje o las técnicas de promoción de la participación ciudadana directa en procesos decisorios de naturaleza constitucional.

Finalmente, y sin aspirar a formular conclusiones irrebatibles derivadas de las anteriores premisas y sin tratar de abrazar ningún sofisma que llevase a pensar que lo aquí postulado va a suplir la resolución judicial de conflictos territoriales, se esbozarán unas pautas que pudieran ser de utilidad para mitigar el número de conflictos territoriales, así como la virulencia de los mismos, especialmente los que se generan en países democráticos y constitucionales, en particular los acaecidos en España.

Este trabajo es el primer peldaño de un proyecto más amplio que busca articular un estudio comparado de mecanismos para y prejudiciales en aras a la resolución de los conflictos territoriales. En particular, se centrará en estrategias integradas en las relaciones intergubernamentales, en los cauces habilitados por una fuente normativa de crucial importancia -las Constituciones de los Estados federados o los Estatutos de autonomía- y en fórmulas con gran atractivo mediático, pero de eficacia pendiente de probar como son las convenciones constitucionales, mecanismo de apertura de la reforma constitucional a la participación directa de los ciudadanos. Siendo nuestro objetivo fundamental contribuir a afrontar los conflictos territoriales desarrollados en España, no obviaremos puntuales referencias a otros Estados.

\section{UN CONTEXTO CONSTITUCIONAL GLOBAL}

La necesidad de incorporar un prisma global a cualquiera de las soluciones que se ideen a los problemas territoriales es un prius del que hemos de partir inexorablemente.

El rápido crecimiento de complejas interconexiones, interdependencias, e interrelaciones entre Estados y sociedades, sobre todo a partir de la caída del muro de Berlín en 1989 y la posterior desaparición de la URSS, ha supuesto el surgimiento de nuevos y/o diferentes poderes y esferas de poder. De este modo la globalización, el proceso de globalización, «denota la expansión y profundización de las relaciones sociales e institucionales a través del espacio y el tiempo, de forma tal que, por un lado, las actividades cotidianas resultan cada vez más influidas por los hechos y acontecimientos que tiene lugar del otro lado del globo, y

2 Sobre este particular, vid. ROIG MOLÉS, E. (2015). "Contenido y eficacia de los acuerdos de las comisiones bilaterales en el procedimiento del artículo 33.2 LOTC”, Informe comunidades autónomas, 2015, pág. 40. 
por el otro, las prácticas y decisiones de los grupos y comunidades locales pueden tener importantes repercusiones globales». (Held, 1997:42).

La transformación que sufre el Estado, entendido como el marco de referencia normativa, la máxima expresión de la soberanía, tiene su reflejo en su Constitución dado que se viene produciendo una pérdida paulatina de la "capacidad efectiva para imponer límites materiales al ejercicio de un poder que ya no es sólo estatal» (Stolleis, et al, 2013:17). Ese detrimento del poder estatal es favorable a las esferas supraestatales, internacionales y, en consecuencia, forma un derecho internacional global, soberanía jurídica internacional/global. Así «una Constitución puede tener primacía ante el Derecho nacional, pero no frente a otros Estados, y menos aún frente al Derecho supranacional de observancia preferente» (Stolleis, et al, 2013:95).

Podemos decir que la globalización «reconstruye, reformula y transforma el poder y la autoridad de los gobiernos nacionales, generando un nuevo régimen de soberanía estatal» (Tewbner, et al, 2010:29) de ese modo articula un conjunto de normas complejo y que además «exige demasiado a las Constituciones nacionales; los espacios jurídicos y políticos de decisión se estrechan cada vez más [...]» (Stolleis, et al, 2013:110). En ese marco nacen nuevos organismos técnicos y especializados ${ }^{3}$, nuevas formas de resolución de conflicto, que habrán de ser tenidos en cuenta por los Estados. Estados cuyas constituciones se perciben debilitadas para resolver los conflictos que surgen en su territorio.

Así, la Constitución que tiene su origen en dos líneas de pensamiento, en dos ideas, (Vega, 1985:15-16) que se entrelazan o relacionan: la idea del pacto o contrato que permite configurar el concepto de autonomía o regulación, organización, se trata de un compromiso jurídico-político y la idea relativa a la limitación del poder, se han visto afectadas por el imparable e irreversible proceso globalizador. La Constitución se filamenta en distintas categorías: poder constituyente, separación de poderes y control de constitucionalidad, derechos fundamentales y supremacía de la Constitución (Ramírez, 2007:1-35). La primera referida al poder constituyente, se debe a la inclusión de nuevos actores, nuevas formas de pensamiento, nuevas o renovadas maneras de entender los conceptos tradicionales que configuran el Estado. Una segunda categoría sería la relativa a la separación de poderes, la tecnocracia, la proliferación de Tratados, la cesión de soberanía, presuponen un déficit democrático. El control de constitucionalidad y de derechos fundamentales obliga a que los propios Tribunales Constitucionales se adecuen a los nuevos derechos, a las decisiones de otros Tribunales con los cuales dialogan ${ }^{4}$. Por último, la superioridad de la Constitución, la soberanía jurídica del Estado se encuentra menoscabada por diversas regulaciones que se imponen de forma cuasi imperceptible. El llamado «soft law», la «lex mercatoria», las imposiciones de los organismos financieros internacionales e incluso los mecanismos de «justicia paralelos al Estado» son manifestaciones de este nuevo derecho «extra costitutione».

Unido a esta idea de transformación constitucional, consecuencia de la globalización, se encuentra la idea de la constitucionalización de la comunidad internacional. De este modo, al hablar de Constitución daríamos cabida no sólo al ámbito estatal, conocido tradicionalmente, sino también a las esferas supraestatales, transnacionales «el orden político territorial y el ordenamiento jurídico formaban una unidad en la fórmula orientadora Estado de Derecho. Tal unidad, ya no puede ser mantenida a la vista de la autonomía del Derecho europeo y de la creciente autonormación del Derecho internacional, con lo que los Estados ya no resultan los señores de los Tratados, sino también sus siervos, y concurren con otros actores en la fijación de normas que, a veces suponen ya un "Derecho global sin Estado"» (Peters, et al, 2010:31).

Se podría advertir que la globalización sitúa al Estado, a los organismos infraestatales y a los supraestatales, en una posición de interdependencia e interrelación que hace imprescindible su cooperación, más aún cuando lo que se nos plantea es un conflicto. Así mismo somos conscientes de como ese multinivel trata de copiar aquellas instituciones, pautas de funcionamiento, etc. que han mostrado su validez. Es por ello que, a la hora de aproximarnos al estudio de mecanismos o estrategias de resolución de conflictos a nivel global, internacional, éstas pueden ser observadas e implementadas desde los niveles infraestatales.

\footnotetext{
3 Sirvan a modo de ejemplo los Consejos Económicos y Sociales, las instituciones de mediación en las distintas administraciones públicas como pueda ser la mediación en la Tesorería General de la Seguridad Social, mediación en el ámbito familiar, intercultural, escolar, jurídico, etc e incluso, los concejos abiertos o los movimientos participativos en las comunidades de vecinos a partir de los años sesenta y setenta en Estados Unidos de América.

4 XIOL RÍOS, J. A. (2013). "El diálogo entre Tribunales". Tribunal Constitucional y diálogo entre tribunales: XVIII Jornadas de la Asociación de Letrados del Tribunal Constitucional, Madrid, Centro de Estudios Políticos y Constitucionales, págs. 11-56.
} 


\section{CONFLICTOS: SUS DENOMINADORES COMUNES}

Existe conflicto o controversia ${ }^{5}$ con implicaciones territoriales cuando se producen desacuerdos entre dos o más sujetos de Derecho sobre cuestiones jurídicas y/o políticas enfrentando de este modo los distintos intereses o pretensiones de los sujetos implicados, generalmente los Estados o territorios dentro de un mismo Estado.

Observamos una doble tipología de controversias, jurídicas y políticas, sin embargo, lo común es que ambas esferas se encuentren relacionadas y debamos hablar del carácter mixto de los conflictos:

Las controversias jurídicas son aquellas que pueden ser resueltas mediante la aplicación del Derecho vigente: la interpretación de un Tratado, de una Constitución o Estatuto. Se refiere a hechos que constituyan la violación de un Derecho nacional o Internacional y a las preceptivas reparaciones por el quebrantamiento de una obligación jurídica.

Las controversias políticas son aquellas cuya solución requiere una modificación en la aplicación del Derecho en vigor o de la interpretación del mismo. Un ejemplo de este tipo de controversias puede ser aquella que deriva de disputas motivadas por la seguridad, el régimen o sistema de gobierno, su organización o su legitimación.

Varios factores, internos y externos afectan al desarrollo del conflicto: los sujetos enfrentados, sus relaciones, la naturaleza del problema, la circunstancia ambiental, la historia conflictual, etc. Ello, a su vez, condicionará la estrategia que se ha de seguir a la hora de resolver el mismo: evitación, colaboración o enfrentamiento; y los medios o sistemas de resolución de conflicto que van a ser utilizados, su carácter político o jurídico: negociación, investigación, mediación, conciliación, arbitraje, arreglo judicial, integración de nuevos sujetos. En todo caso, dos son los principios que han de operar ante la existencia de conflicto: la solución pacífica de los conflictos $^{6}$ y la libertad de elección de medios para llegar al arreglo. De ambos pende la eficacia del proceso.

\subsection{Principios de «solución pacífica de los conflictos» y de «libre elección de medios»}

A la hora de enfrentarse a una controversia o un conflicto, tradicionalmente se distinguía entre medios pacíficos y no pacíficos de resolución ${ }^{7}$, sin embargo, a partir de la Segunda Guerra Mundial ${ }^{8}$ y concretamente con la Carta de Naciones Unidas existe la prohibición del uso o amenaza de la fuerza, obligando a la resolución de las controversias por medios pacíficos para garantizar la paz y seguridad internacional, para «preservar las generaciones venideras del flagelo de la guerra» ${ }^{9}$.

Cierto es que junto al principio de solución pacífica de las controversias opera el principio de libre elección de los medios, dejando a voluntad de los sujetos en conflicto la elección de los distintos sistemas de resolución y garantizando así la independencia e igualdad soberana de las partes enfrentadas. Este principio de libertad cobra un protagonismo primordial cuando se trata de optar por diferentes medios de resolución prejudicial o parajudicial y es de gran relevancia en los conflictos territoriales, hasta el punto que condicionan la viabilidad de todo el proceso.

Consecuencia de la operatividad de estos dos principios, los distintos organismos que supervisarían esos procesos tratan de incrementar medios o sistemas preventivos, el uso de la mediación y del arbitraje frente a la posibilidad de que existan conflictos que pongan en peligro otros bienes jurídicos como la estabilidad estatal y la seguridad. Y sólo en caso de imposibilidad de solucionar dicho conflicto se produce el recurso a los instrumentos judiciales, en el ordenamiento jurídico español, y tal y como se analizará en el quinto punto del presente artículo, el Tribunal Constitucional.

\subsection{Sistemas de resolución de conflictos como referente global}

El Derecho Internacional Público y el Derecho particular de diferentes Estados nos ofrecen varios sistemas de resolución pacífica de conflictos, garantizando, en la medida de lo posible, el buen entendimiento

\footnotetext{
5 Tribunal Permanente de Justicia Internacional asunto Mavrommatis (CPJI Serie A, núm. 2, 1924) en Palestina (Grecia c. Reino Unido), sentencia del 30 de agosto de 1924. Disponible en: www.icj-cij.org.

${ }^{6}$ Carta de Naciones Unidas, Capítulo VI, arts.33 y ss. Disponible en: http://www.un.org

7 Convención (IV) de La Haya, de 18 de octubre de 1907 relativa a las leyes y costumbres de la guerra terrestre.

${ }^{8}$ A partir de la Primera Guerra Mundial comenzaría ese íter prohibitivo si bien su refuerzo vendrá de la mano del artículo 2.4 de la Carta de Naciones Unidas, de 1945.

${ }^{9}$ Carta de Naciones Unidas, Preámbulo, párrafo $1 .^{\circ}$. Disponible en: http://www.un.org.
} 
entre las partes enfrentadas y el no uso de la fuerza. Sin embargo, para que se produzca la voluntad de arreglo ha de operar el principio de buena fe por las partes implicadas en el conflicto, esto es, la verdadera intención de llegar a un entendimiento ${ }^{10}$. Así mismo, cabe decir que si mediante el uso de uno de los sistemas de resolución pacífica de conflictos no se llegase a conseguir el pretendido acuerdo, esto es, el fin de las disputas, podría iniciarse un nuevo intento mediante otro procedimiento negociador hasta dar con la solución, tomando como límite infranqueable el uso o amenaza de la fuerza ${ }^{11}$.

Entre los sistemas pacíficos de resolución de controversias que nos ofrece el Derecho global podemos destacar los siguientes ${ }^{12}$ :

\section{A) Negociación}

La negociación ${ }^{13}$ consiste en la solución de las controversias, de rutina principalmente, entre dos o más partes mediante la comunicación directa de éstas. La negociación diplomática directa suele utilizarse como uno de los primeros sistemas de resolución de conflictos a escala global dado que supone la comunicación, la consulta o el intercambio de pareceres entre los altos miembros del ejecutivo con potestades para ello a fin de encontrar una solución negociada al problema común ${ }^{14}$.

Para que podamos hablar de este sistema como un medio propicio a la hora de resolver un conflicto han de producirse varias circunstancias, desde la buena fe por ambas partes hasta el reconocimiento mutuo pasando por el ejercicio de libertad y responsabilidad que se espera de los sujetos implicados. La negociación es un sistema propicio para ser utilizado en las fases iniciales del conflicto en cuanto que actúa a nivel preventivo, así como también para conflictos rutinarios de carácter más bien político, aunque no necesariamente, pues la flexibilidad y la discrecionalidad que operan suma a la inmediatez, celeridad y a la cooperación por las partes enfrentadas.

Al hablar del sistema de negociación diplomática debemos aludir a dos Resoluciones de la Asamblea General de las Nacionales Unidas pues en ellas se establece las pautas y principios que han de inspirar al sistema de resolución de conflictos que nos ocupa: Resoluciones de la Asamblea General de la ONU 37/10 «declaración de Manila sobre el arreglo pacífico de las controversias internacionales» ${ }^{15}$ y 53/101 «principios y directrices para las negociaciones internacionales» ${ }^{16}$.

En las Resoluciones 53/101 de 8 de diciembre de 1998 y 37/10 de 15 de noviembre de 1982, se establece la negociación como un método flexible y eficaz a la hora de resolver pacíficamente las controversias entre los Estados y como método de creación de nuevas normas internacionales de conducta. Entre los principios que enuncian y que reafirman se encuentra el de igualdad soberana de todos los Estados, el de independencia e integridad territorial, a partir de los cuales se derivaría la prohibición o recomendación de no intervenir, directa o indirectamente, en los asuntos de jurisdicción interna de los Estados y la prohibición del uso o amenaza de la fuerza e incluso el no reconocimiento de los territorios ocupados por ese uso de la fuerza. Junto a ello los principios de cooperación y buena fe han de guiar el procedimiento a fin de mantener un ambiente constructivo y de abstenerse de comportarse de manera tal que se dificulte el avance de las

10 Resolución 2625 (XXV) de la Asamblea General de Naciones Unidas, de 24 de octubre de 1970, que contiene la Declaración relativa a los Principios de Derecho Internacional referentes a las relaciones de amistad y a la cooperación entre los Estados de conformidad con la Carta de las Naciones Unidas. Disponible en: http://ocw.um.es.

11 Resolución 37/10 de la Asamblea General de las Naciones Unidas. Declaración de Manila sobre el Arreglo Pacífico de Controversias Internacionales, Punto 13. «Ni la existencia de una controversia ni el fracaso de un procedimiento para el arreglo pacífico de una controversia será motivo para que cualquiera de los Estados partes en tal controversia recurra a la fuerza o a la amenaza del uso de la fuerza».

12 Para desarrollar este apartado se han consultado los siguientes artículos: El Concepto de conflicto y los medios de Solución de Controversias en el Derecho Internacional Gobbi, Javier. Disponible en: www.caei.com.ar y Derecho internacional público: La solución pacífica de las controversias internacionales Muhiar, Hanady. Disponible en: http://www.gloobal.net. López Martín, Ana Gemma (2013), «El arreglo de las controversias territoriales por la Corte Internacional de Justicia. Una aproximación a sus líneas directrices», en REDUR II, diciembre, pp. 55-72.

${ }_{13}$ Ampliación de información en: http://www.un.org/undpa/en.

14 Un ejemplo de este sistema en clave española sería la Declaración de principios entre España, Marruecos y Mauritania sobre el Sahara occidental, celebrada en Madrid, a 14 de noviembre de 1975. Documento disponible en: http://peacemaker.un.org/mauritaniamorocco-spain-principles 75 .

15 Resolución 37/10 de la Asamblea General de las Naciones Unidas. Declaración de Manila sobre el Arreglo Pacífico de Controversias Internacionales. Disponible en: http://www.dipublico.org.

16 Resolución 53/101 de la Asamblea General de las Naciones Unidas. Principios y directrices para las negociaciones internacionales. Disponible en: http://www.dipublico.org. 
negociaciones, siendo necesario establecer unas pautas $u$ objetivos principales a conseguir. Negociaciones que han de terminar en una solución aceptable y justa para todas las partes enfrentadas.

\section{B) Investigación}

La investigación o encuesta ${ }^{17}$ supone el esclarecimiento de la realidad de los hechos que dieron origen al conflicto. De forma voluntaria, se somete el dilema a la comprobación por un tercero imparcial, que puede ser un sujeto de derecho internacional, nacional -pensemos en otra Comunidad Autónoma distinta a las que sostienen un potencial conflicto- o una comisión de investigación ad-hoc diferente a las de naturaleza parlamentaria ${ }^{18}$, de la realidad de los hechos puestos en cuestión u originarios de la controversia quien sin entrar en la calificación jurídica de lo que pasó emite un informe no vinculante para las partes.

\section{C) Mediación}

La mediación ${ }^{19}$ supone la petición, por parte de uno de los protagonistas del conflicto, de la intervención de un tercero imparcial quien mediante el conocimiento de la controversia procura acercar a las partes, interviene directamente en las conversaciones y en el desarrollo del problema y sugiere términos de arreglo, a modo de consejo ${ }^{20}$ dado que carecen de fuerza vinculante, si bien es cierto también puede derivar en la celebración de un acuerdo entre las partes enfrentadas ${ }^{21}$.

Podemos decir que las partes implicadas en la controversia envían a uno o varios sujetos, órganos o representantes del mismo a la mesa de negociación en la que ese tercero amigable ha de contar con una serie de derechos y ha de someterse a unas directrices a fin de asegurar el buen entendimiento y aconsejar a las partes en conflicto.

Un ejemplo de este sistema sería el conflicto territorial de la Isla Perejil entre España y Marruecos en 2002 cuya representación vendría de la mano de la ministra de Exteriores española, Ana Palacio y Mohamed VI respectivamente y como mediador el secretario de Estado Colin Powell, en representación de Estados Unidos.

Una vez esbozado el sistema de mediación, cabe definir cuáles son los derechos y deberes que afectan al mediador y para ello hemos de apoyarnos en la Carta de Naciones Unidas; el Código de Conducta Europea para mediadores; la Directiva 2008/52/CE del Parlamento Europeo y del Consejo de 21 de mayo de 2008 sobre ciertos aspectos de la mediación en asuntos civiles y mercantiles ${ }^{22}$; la Resolución del Parlamento Europeo, de 13 de septiembre de 2011, sobre la aplicación de la Directiva sobre la mediación en los Estados miembros, su impacto en la mediación y su aceptación por los Tribunales; la Ley 5/2012, de 6 de julio de mediación en asuntos civiles y mercantiles 23 ; el Real Decreto 980/2013 por el que se desarrollan determinados aspectos de la Ley 5/2012, de mediación en asuntos civiles y mercantiles; y en el ámbito autonómico cabe destacar la Ley 1/2011 de 28 de marzo de mediación de la Comunidad Autónoma de Cantabria.

De este modo entre los derechos de que dispone el mediador destacaremos: el derecho a recibir la información necesaria para tener un conocimiento extenso y exhaustivo de la controversia, esto es ha de

17 Resolución 46/59 de la Asamblea General Declaración sobre la determinación de los hechos por las Naciones Unidas en la esfera del mantenimiento de la paz y la seguridad internacionales. Disponible en: http://legal.un.org.

${ }^{18}$ En este sentido el Convenio de la Haya de 1907 prevé en sus artículos 17 y ss. la creación de una Comisión de investigación.

19 GARCÍA GÉRBOLES, L. y MUESMANN TORRES, M. (2010). "El entronque histórico-jurídico del concepto de la mediación desde el derecho romano hasta la actualidad", La mediación: presente, pasado y futuro de una institución jurídica. Oleiros (La Coruña), Netbiblo.

${ }^{20}$ Este es un método híbrido entre la mediación diplomática y la conciliación, puesto que al igual que en la mediación diplomática se presume un ambiente con cierta discrecionalidad, sin tensiones excesivas, de entendimiento y cooperación, es por ello que la voluntariedad y la motivación de las partes para resolver la controversia se convierte en factor fundamental, dado que si las partes no tienen voluntad de resolver el conflicto por mucho que la otra parte y el mediador lo intente éste no llegará a buen fin.

${ }^{21}$ Convención de las Naciones Unidas contra la corrupción. Nueva York, 2004. Artículo 66. 1 Solución de controversias. «Los Estados Parte procurarán solucionar toda controversia relacionada con la interpretación o aplicación de la presente Convención mediante la negociación».

22 BERLINGUER, A. (2013): "Hacia un modelo europeo de mediación", Revista Aranzadi Doctrinal, 5:195-203 / LÓPEZ-BARAJAS PEREA, I. (2012): "La mediación civil y mercantil y sus garantías: un paso más en la creación de un espacio judicial europeo”, Revista General de Derecho Europeo, 27.

${ }^{23}$ Sobre este particular, Vid. MARTí MINGARRO, L. (2013): "La mediación civil y mercantil en la nueva Ley 5/1012, de 6 de julio", Revista Jurídica de Castilla de León, 29. 
conocer el conflicto en sus orígenes, en su contenido (reclamaciones, pretensiones) y en su evolución (documentación derivada de posibles negociaciones anteriores); tiene derecho a participar directamente en las negociaciones y a presentar métodos o fórmulas alternativas de resolución; así mismo tiene derecho a que conste en el protocolo, acuerdo, tratado o convenio resultante, que ha sido mediador.

Si bien frente a los derechos existen una serie de debere ${ }^{24}$ que ha de cumplir: estudiar en profundidad y de manera imparcial el conflicto, obrar con objetividad, imparcialidad e independencia ${ }^{25}$; implicarse en el desarrollo del conflicto a fin de tratar de solventar o suavizar las dificultades y los enfrentamientos que se presenten; debe participar directamente en las negociaciones en las cuales ha de estar presente; no puede ejercer coacción sobre ninguna de las partes para imponer total o parcialmente su voluntad por lo que además ha no ha de tener intereses en el asunto a resolver.

Unido a los derechos y deberes del mediador existen otros factores condicionantes del procedimiento, así, la motivación, la voluntad, es un factor fundamental en la mediación ya que afecta no sólo al proceso en sí sino también a la elección de la estrategia que ha de seguir el mediador ${ }^{26}$. Sin embargo, no es el único factor implicado dado que la relación existente entre las partes enfrentadas también cobra gran importancia. Así, si hablamos de Estados pertenecientes a un mismo régimen, una misma asociación u organización internacional, puede ser favorable o en beneficio del proceso de resolución dado que se pondría en valor el coste que puede ocasionar al resto del grupo el hecho de que no se solucione la controversia. Empero, puede darse la circunstancia de que sólo una de las partes enfrentadas o ninguna pertenezcan a este grupo, asociación, organismo, suponiendo un mayor esfuerzo de mediación ${ }^{27}$ y que la estrategia a seguir sea distinta al primer supuesto (Bercovitch, 1989:284-299).

Bercovitch y Houson (Bercovitch y Houston, 2000:170-202) han establecido una triple categoría de estrategias a seguir por los mediadores a la hora de afrontar un conflicto: Comunication-facilitation, Procedural-formative y Directive strategies. De este modo los mediadores podrán elegir la estrategia a aplicar en función de sus capacidades, del contexto del conflicto y de la motivación que existe por las partes para resolver la controversia.

Comunication-facilitation, esta estrategia tiene como notas características el contacto con las partes, ganar su confianza y respeto, conseguir que ambas partes mantengan contacto e interactúen, obtener un entorno de entendimiento, identificar las cuestiones e intereses, esclarecer la situación, dejar que se discutan los distintos intereses de las partes, evitar tomar partido, ofrecer la información que falta o corregir aquella información errónea, facilitar evaluaciones positivas y redactar un informe.

Procedural-formative, en este tipo de estrategias el mediador toma el control del escenario donde se va a proceder a desarrollar la mediación, controla el lugar, la estructura de la agenda y el suministro de información sobre el progreso. Sus notas características son: la elección del lugar en el que se va a desarrollar la mediación, asegurar que exista tranquilidad, paz y formalidad en las reuniones, mantener a las partes en la mesa de negociación, controlar el ambiente físico, establecer protocolos y seguir los procedimientos, resaltar los intereses en común y reducir las tensiones, controlar los tiempos, comenzar con aquellas cuestiones más simples, estructurar la agenda y mantener la atención en los puntos u objetivos de discusión.

Directive strategies, en este supuesto los esfuerzos del mediador se concentran en el contenido y en la sustancia del proceso de negociación incentivando a las partes o dándoles ultimátums. La estrategia directa trata o pretende conseguir el cambio de comportamiento de las partes enfrentadas. Entre las tácticas asociadas a esta estrategia podemos encontrarnos: conseguir el cambio de expectativas de las partes, ser responsable de las concesiones que han de hacer las partes, hacer sugerencias y proposiciones significativas, hacer conscientes a las partes de los costes que pude ocasionar el no llegar a un entendimiento o acuerdo, facilitar información, ayudar a diseñar un entorno aceptable para que se alcancen resultados, cambiar las percepciones y empujar a las partes para que se muestren flexibles, ofrecerse a verificar el cumplimiento de los acuerdos alcanzados.

Frente a la visión de Bercovitch y Hudson atendemos a las categorías clásicas de la mediación, a saber: modelo Harvard, modelo transformativo y modelo circular narrativo, siguiendo los postulados planteados por Munné Catarina, F y Vidal Teixidó, A. (Munné Catarina, F y Vidal Teixidó, A., 2013: 190:200).

${ }_{24}$ Directiva 2008/52/CE del Parlamento Europeo y del Consejo de 21 de mayo de 2008 sobre ciertos aspectos de la mediación en asuntos civiles y mercantiles. Artículo 3.

${ }^{25}$ Código de Conducta Europea para mediadores.

${ }^{26} \mathrm{Y}$ en este sentido es muy importante el papel que desarrolla la ONU, concretamente su grupo de mediadores: http://peacemaker.un.org/mediation-support/stand-by-team.

27 Pensemos en el Conflicto colombiano con las FARC. 
Si partimos de tomar el conflicto como un problema de las partes que tiene que ser resuelto sin importar el porqué ni el quién del mismo, interesándonos sólo su resolución (modelo Harvard), el mediador debe restablecer el equilibro y procurar cambiar la actitud conflictiva para llevar a las partes a la cooperación. Se advierte una deficiencia en el modelo Harvard relativa a la poca implicación o a la no introducción en el conflicto y a que se da la espalda a la causa que lo motiva, siendo un modelo utilitarista y poco sensible. Así lo importante es solucionar el problema inmediato, solución rápida y económica del conflicto, a pesar de que el mismo siga latente.

Cuando no sólo se persigue solucionar el conflicto, sino confirmar su existencia a fin de cambiar la situación y el entorno conflictivo que ha dado lugar al mismo (modelo Transformativo) se procederán a acentuar los aspectos humanos de la mediación ${ }^{28}$. «Si para el modelo Harvard el conflicto es un elemento negativo que hay que evitar, para el modelo transformativo el conflicto es un exponente de cambio, y hay que tenerlo en cuenta en la relación al entorno físico donde se encuentra, es decir, el contexto, la especificidad cultural y la propia relación de las partes» ${ }^{29}$. Teniendo como inconveniente que las partes puedan considerar la mediación como una pérdida de tiempo debido a su dilatación en el tiempo, esto es a la no inmediatez.

Como matización de los anteriores se erige un nuevo modelo diferenciado, modelo Circular Narrativo, que se centra fundamentalmente en la comunicación e interacción de las partes, para ello pretende aumentar las diferencias entre las partes en conflicto a fin de inducir al caos en el orden establecido y de ese modo poder flexibilizar el sistema previamente dado para que surjan nuevas estructuras, un nuevo orden. Aporta un mejor conocimiento de las personas y de las relaciones que se producen en la mediación dado que, como señalan los autores, da mayor importancia a la comunicación y a las partes como artífices exclusivos de una historia alternativa. Por ello es considerado opuesto al modelo Harvard. Su aspecto negativo es que no se preocupa propiamente del conflicto sino de la creación de una historia nueva y las consecuencias son impredecibles.

\section{D) Conciliación}

La conciliación supone igualmente la intervención de un tercero imparcial. En ese caso se habilitaría una Comisión de conciliación creada ex profeso, ante la cual se expondría el conflicto. Es un sistema de resolución de conflictos más formal y menos flexible que la mediación, dado que en este caso la Comisión ${ }^{30}$ investiga los fundamentos de hecho y las normas de Derecho aplicables así como la totalidad de los elementos que suscitan la controversia a fin de emitir un informe no vinculante en el cual se proponen los términos jurídicos de solución.

\section{E) Arbitraje}

El arbitraje ${ }^{31}$ es un procedimiento «cuasijudicial» en el cual las partes enfrentadas designan dos sujetos o entidades, quienes a su vez señalan un tercer árbitro (órgano unipersonal o colegiado) que puede ser el presidente del «tribunal» ad hoc. Dicho tribunal arbitral emitirá su decisión, laudo arbitral, inapelable y obligatoria para las partes, pudiendo fallar en derecho, o en equidad, principios de ética o reglas generales de derecho no codificado.

Este sistema puede ser pactado mediante tres formas: la cláusula de arbitraje, las cláusulas compromisorias y los compromisos de arbitraje. (Sáez Hidalgo I. y Dorrego de Carlos, A. Coord.: 2013).

La cláusula de arbitraje se trata de una cláusula o articulado, contenida en una norma generalmente específica, de sometimiento obligatorio al procedimiento de arbitraje en el cual las partes signantes concluyen las normas y pautas que servirán para el establecimiento del arreglo.

${ }_{28}$ Bush y Folger consideran que la mediación contiene un potencial único para transformar el conflicto a través del cambio de la actitud mental de las partes. Vid. MARQUÉS CEBOLA, C. (2013). La mediación. Madrid: Marcial Pons. pág. 195.

${ }_{29}$ MUNNÉ CATARINA, F. y VIDAL TEIXIDÓ, A., (2013). La mediación: resolución pacífica de conflictos, régimen jurídico y eficacia procesal. Madrid: La Ley. p.195.

30 La Convención de Viena sobre Derecho de los Tratados, de 23 de mayo de 1969, prevé una Comisión de Conciliación en su Anexo. Disponible en: http://www.derechos.org.

${ }_{31}$ Su origen suele ser datado de 1794 respecto al Tratado de Jay, firmado en Londres el 19 de noviembre de1794 entre USA y Gran Bretaña. Tratado disponible en: https://memory.loc.gov. 
Las cláusulas compromisorias se establecen en el clausulado de una norma a priori sobre los conflictos que deriven de él. Sin que tengan que ser exclusivamente específica sobre el sometimiento al arbitraje, esto es, también general, sometimiento al arbitraje con independencia de la materia.

Los compromisos de arbitraje surgen a posteriori del nacimiento del conflicto, existiendo la obligatoriedad del sometimiento al arbitraje por lo que se recurre al principio de libre elección, pero con las condiciones indicadas sobre cómo se llevará a cabo, objetivos, composición del «tribunal», poderes otorgados al tribunal arbitral y derecho aplicable.

Si bien, esta triple categoría puede ser agrupada en dos, en función de su carácter previo a la controversia, cláusula de arbitraje y cláusula compromisoria, o bien posterior, suscripción de un compromiso arbitral.

La composición del órgano arbitral se deriva del acuerdo entre las partes en conflicto pudiendo ser unipersonal o multipersonal, en este caso se distinguen tres tipos de composiciones: la existencia de un órgano unipersonal, un árbitro único que suele identificarse con un Jefe de Estado, diplomático o jurista de reconocido prestigio; o bien colegiado en cuyo caso distinguimos entre comisión mixta compuesta por representantes de las partes enfrentadas y por personas ajenas a las mismas; o por un tribunal arbitral compuesto por personas externas a los implicados, generalmente formado por tres o cinco miembros.

Las reglas de procedimiento son generalmente adoptadas por las partes en su acuerdo compromisorio, un convenio, aunque en ocasiones dejan dicha cuestión al arbitrio del órgano arbitral. Empero, existen ciertos principios que guían el mismo: el principio de libertad de elección del procedimiento, el principio de igualdad procesal, principio de representación de las partes, principio de elección de los representantes árbitros y/o jueces. Así mismo, debemos precisar que el procedimiento se divide en dos partes una primera de instrucción escrita y la fase oral. La fase escrita supone el examen de documentación y remisión de memorias e informes sobre origen y evolución del procedimiento, así como del derecho que se habría de aplicar en su caso, se remiten las memorias a las partes que serán contestadas con las contramemorias. En la fase subsiguiente de debate se procede a la exposición oral de las cuestiones en litigio, de las bases de defensa, de las pretensiones.

El laudo o resolución arbitral se redactará por escrito y habrá de estar motivado y fundado en Derecho o equidad, se adoptará por mayoría si atendemos a un órgano colegiado, pudiendo existir votos particulares y tiene carácter secreto. El laudo o sentencia arbitral habrá de ser cumplida en plazo y forma establecidos.

En este apartado de carácter procesal procede recuperar alguna de las instituciones que se utilizan y sobre cuya virtualidad en el marco de la resolución de conflictos territoriales ad intra, se nos antoja con muchas posibilidades. Así, la aquiescencia, el estoppel y la fecha crítica. La que se presenta como una fórmula innovadora «acuerdo tácito+aquiescencia» (López Martín 2013: 61) apunta a la posibilidad de alcanzar de facto un acuerdo, que no llega a formalizarse, pero al que nos acercamos desde el comportamiento recíproco de las partes que asienten y consienten sobre la propuesta. Otra técnica especialmente relevante que se centra en el comportamiento de las partes es la denominada estoppel. Con ese anglicismo se alude a un principio del rule of law en virtud del cual se prohíbe que una parte aluda a hechos que son contrarios a sus primeras pretensiones o acciones. Conceptualmente, el estoppel es un mecanismo que protege a las partes de ser injustamente confundidas por la inconsistencia de las alegaciones o propuestas de la otra parte. Finalmente, la importante institución procesa de la «fecha crítica» implicaría fijar de antemano los límites temporales de la disputa. Esa datación sería de obligado respeto quedando manifiesto interdecir argumentos o hechos anteriores o posteriores a las mismas.

\section{F) Convención constitucional: la vía de la participación ciudadana}

El fomento de la participación ciudadana en los asuntos públicos es una coordenada que parece marcar el devenir en que se desenvuelve el presente del Derecho y de la Administración. Lejos de la acepción clásica de convención constitucional, vinculada a las fuentes del derecho anglosajón, la expresión «convención constitucional» vinculada al ámbito participativo alude, desde un realismo que nos lleva a los Estados en que se ha aplicado, como Irlanda, Australia o Canadá, a una reunión o agrupación de ciudadanos y sus representantes, avalados por precedentes organizativos similares y determinados por el compromiso político de gobernabilidad basado en el poder discrecional del ejecutivo, que actúan con la finalidad de dotar de un suplemento al contenido normativo de la Constitución, a otra norma, o a una situación conflictiva política y territorialmente, a los efectos de potenciar su flexibilidad, adoptándolas a las circunstancias cambiantes de la 
vida, a unas nuevas necesidades (Seijas Villadangos 2012: 424). Con ella se reforzaría esa parte eficiente, presente en cada Constitución ${ }^{32}$.

La propuesta que formulamos consiste en utilizar el contexto político de un disenso, de un conflicto territorial, para recabar directamente el parecer de los ciudadanos sobre ese desencuentro. Desde la referencia del caso más cercano en el tiempo y en el espacio y más afín en el objeto, el irlandés ${ }^{33}$, podemos desgranar algunas claves de esta iniciativa. Formalmente, se integraría una comisión ${ }^{34}$ elegida entre voluntarios, merced a un proceso aleatorio en el que se buscase una amplia conexión a la sociedad en términos de género, edad, status social y geográfico. Ésta se acompañaría de unos asesores, conductores, que les apoyarían en la obtención de información y documentación, pero que se abstendrían de participar activamente en los debates a los efectos de no condicionar las decisiones. La asamblea de ciudadanos fijaría un guion sobre los aspectos más esenciales del conflicto y postularían unas soluciones. Materialmente, sus propuestas se remitirían a sede parlamentaria para su conocimiento por la Cámara y por el ejecutivo. Cabría, si el ejecutivo lo valora, ampliar el ámbito de la consulta convocando un referéndum sobre esas propuestas, o bien propiciar su formalización, mediante un proyecto de ley o una proposición de ley, un borrador de acuerdo o convenio o cualquier otro formato que le confiera seguridad jurídica.

En esta tónica se sitúa la reciente Orden PRE/1590/2016, de 3 de octubre, por la se publica el Acuerdo del Consejo de Ministros de 30 de septiembre de 2016, por el que se dictan instrucciones para habilitar la participación pública en el proceso de elaboración normativa a través de los portales web de los departamentos ministeriales (BOE de 5 de octubre de 2016). Aquí buscaríamos un campo de aplicabilidad más amplio y una mayor sistematización en su implementación.

\section{CONFLICTOS TERRITORIALES}

\subsection{El denominador común de los conflictos territoriales a tenor de los supuestos prácticos: Quebec, País Vasco y Cataluña}

Canadá se presenta como un relevante patrón en la búsqueda de un equilibrio constitucional en su esfuerzo por producir la integración de la diversidad (nacional, lingüística, cultural, institucional, jurídica y política) (Seijas Villadangos 2001: 227).

El caso canadiense es especialmente relevante porque se plantea en un contexto de constitución escrita, rígida y jerárquicamente superior a las leyes (Oliver, 2014:462). El reto de la acomodación de Quebec en el Estado canadiense.

En Quebec se han desarrollado dos experiencias de referéndum ligadas al estatuto de Quebec en la Federación, en 1980 y 1995. El intento de avalar con el voto popular una solución a un conflicto territorial.

En el primer referéndum de 20 de mayo de 1980 se plantea una soberanía-asociación entre Canadá y Quebec cuyo resultado fue favorable por un $59,50 \%$ a la permanencia. Fruto de esta coyuntura, y bajo el Gobierno federal presidido por Pierre Trudeau se promulga el 17 de abril de 1982 la nueva Constitución de Canadá, con la oposición del Gobierno quebequés. Con el objetivo de reintegrar Quebec al consenso constitucional, el Gobierno federal promueve reformas constitucionales orientadas a atender algunas reivindicaciones de Quebec que se plasman en los acuerdos de Lago Meech en 1987 y Charlottetown en 1992. La moraleja es la adopción de grandes acuerdos políticos de convivencia, frente al fracaso de radicales retos jurídico-referendarios.

El 30 de octubre de 1995 tiene lugar la celebración de un segundo referéndum, convocado por el Gobierno de la provincia de Quebec sobre un «nuevo partenariado» Canadá-Quebec (Mitjans, Castellà, 2001:94) que es rechazado por un 50,56\% de votos en contra.

Este ajustado fracaso supone el anuncio por parte del Primer ministro quebequés, Lucien Bouchard, de un nuevo referéndum «cuando se den las condiciones ganadoras». Por su parte, el Gobierno de Ottawa propone dos estrategias, la primera de ellas encaminada a una reforma del sistema federal canadiense y a

\footnotetext{
32 BAGEHOT, W., The English Constitution, Collins, London, 1972 (1. ${ }^{a}$ edic. 1867), p. 61.

33 Cfr. http://oireachtasdebates.oireachtas.ie/debates\%20authoring/debateswebpack.nsf/takes/seanad2016071500002?opendoc ument\#T00100.

34 Comisión irlandesa de 2013 compuesta de un número máximo de cien personas, 66 ciudadanos y 33 parlamentarios, junto a un presidente. Sin embargo, su continuación de 2016 otorga un protagonismo excesivo a los cuidadanos. «Citizen Assembly».
} 
satisfacer ciertas reivindicaciones quebequesas y la segunda con medidas orientadas a poner de manifiesto las dificultades que se derivarían de una eventual secesión de Quebec. Dentro de esta segunda estrategia, el Gobierno federal plantea el 30 de septiembre de 1996 unas preguntas al Tribunal Supremo ${ }^{35}$ a través del procedimiento de la opinión consultiva, cuyas respuestas se plasmaron el 20 de agosto de 1998 en la «Reference Re Secession of Quebec».

Algunas de las estrategias apuntadas en el epígrafe anterior se perciben en esta práctica.

El Derecho canadiense a partir del Dictamen de la Corte Suprema de Canadá en relación con la secesión unilateral de Quebec de 1998 y la Ley de claridad de 2000, constituyen los hitos de codificación del procedimiento a seguir en caso de ejercicio del derecho de secesión.

La Corte Suprema parte de considerar que la Constitución canadiense no reconoce un derecho unilateral a la secesión de una provincia, pero al mismo tiempo recuerda la ineludibilidad de la reforma constitucional para incorporar los términos de la secesión de una provincia. Asimismo, establece los cuatro principios fundamentales que inspiran el conjunto de la Norma Fundamental (el principio democrático, que otorga legitimidad a la decisión adoptada; el principio federal, que supone el reconocimiento de Quebec como una de las naciones fundadoras y el carácter bilateral del pacto federal que vincula por igual a todas las partes; el principio de constitucionalidad y Estado de Derecho, que implica que los efectos legales de una decisión democrática legítimamente adoptada no son inmediatos y deben ser canalizados mediante una negociación; y el principio de respeto de las minorías), y que han de regir el proceso de la secesión cuando una provincia se pronunciara a favor.

De ellos, la Corte desprende la obligación de abrir un período de negociaciones políticas entre las dos partes, que deberá respetar dos requisitos: la formulación de una pregunta clara y la exigencia de una respuesta clara de más de una mayoría simple de los electores. La negociación política pasa a ser preceptiva por mandato judicial.

La respuesta fue paralela y se plasmó en sendas leyes aprobadas respectivamente, por el Legislativo federal y por la Asamblea Nacional de Quebec: La Ley de la Claridad y la Ley sobre el Ejercicio de los Derechos Fundamentales y Prerrogativas del Pueblo quebequés y del Estado de Quebec.

Conforme a la Ley de claridad del año 2000 , el gobierno de una provincia puede preguntar a su población sobre cualquier tema, y puede formular la pregunta, si bien establece tres momentos sucesivos en que interviene la Federación: dar conformidad a la pregunta, a priori, función que se atribuye a la Cámara de los comunes del Parlamento federal; la valoración de los resultados obtenidos, a posteriori y fijar requisitos para la propuesta de reforma constitucional.

Asimismo, para poder ser llevada a cabo la consulta, la citada Ley establece una serie de requisitos, entre lo que destaca que no pueden incluirse mandatos de negociación sin ulterior referéndum ni tampoco otras posibilidades distintas de la secesión (art.1.4)

Como culminación a la regulación de la secesión, la ley defiende que no existe un derecho de secesión unilateral de una provincia, y que la misma requiere la modificación de la Constitución de Canadá, para la cual debe haber una negociación en la que deben participar los gobiernos de todas las provincias y el de Canadá. El Gobierno canadiense debe incorporar a la propuesta de reforma constitucional el contenido de las negociaciones sobre los términos de la secesión: reparto de obligaciones, posible modificación de las fronteras de la provincia, derechos de los pueblos aborígenes y la protección de los derechos de las minorías (artículo 3).

La respuesta inmediata del Gobierno de Quebec a la Clarity Act se produjo tan solo dos días después de la introducción de su Proyecto de Ley en la Cámara de los Comunes. El 15 de diciembre de 1999, se presentaba ante el Legislativo quebequés un proyecto de Ley que se formalizaría en la Ley relativa al ejercicio de los derechos fundamentales y prerrogativas del pueblo de Quebec y del Estado de Quebec. Su principal afirmación redunda en sostener el derecho del pueblo quebequés «por sí solo» a determinar el régimen político y el status legal de Quebec.

Cabe destacar dentro de su contenido la fijación de un ambicioso objetivo, «la necesaria reafirmación de los logros colectivos del pueblo de Quebec, las responsabilidades del Estado de Quebec y los derechos y prerrogativas de la Asamblea Nacional con respecto a todos los asuntos que afectan al futuro del pueblo de Quebec».

${ }^{35}$ Las preguntas que el Gobierno federal sometió a la consideración del Tribunal Supremo fueron: ¿Permite la Constitución canadiense la secesión unilateral de Quebec?, ¿Protege el derecho internacional una secesión unilateral de Quebec?, Si las respuestas anteriores fueran contradictorias, ¿qué derecho debería aplicarse? 
Los cuatros artículos que integran el primer capítulo dedicado al pueblo de Quebec constituyen el núcleo del mensaje que se deseaba transmitir con esta norma: la reafirmación en la voluntad de autodeterminación del pueblo de Quebec. Su redacción se asemeja a los textos internacionales más solemnes que históricamente culminaron procesos de independencia, v.gr. La Declaración de Independencia americana de 1776. El artículo de apertura establece que «el derecho del pueblo de Quebec a la autodeterminación está fundado en los hechos y en el derecho. El pueblo de Quebec es titular de Derechos que son universalmente reconocidos bajo los principios de igualdad de derechos y autodeterminación de los pueblos». En consecuencia, (art. $\left.2 .^{\circ}\right)$ «el pueblo de Quebec tiene el derecho inalienable a decidir libremente el régimen político y el status legal de Quebec» ${ }^{36}$.

Con todo, el repudio directo al contenido de la Clarity Act se concentra en los artículos tercero y cuarto. Así, se dispone que «el pueblo de Quebec, actuando a través de sus propias instituciones políticas, determinará por sí solo el modo de ejercer su derecho a elegir el régimen político y el status legal de Quebec. Ninguna condición o modo de ejercicio de tal derecho, en particular la consulta al pueblo de Quebec a través de un referéndum, tendrá efecto a menos que se determine de conformidad con lo establecido en el primer párrafo». Cabría interpretar, ante tales afirmaciones, que el contenido de la Clarity Act supondría una interferencia a esa atribución. En román paladino, se estaría sosteniendo la ilegalidad de la ley federal.

El punto final a este auténtico manifiesto identitario se contiene en la disposición final, señalándose que «ningún otro parlamento o gobierno puede reducir los poderes, autoridad, soberanía o legitimidad de la Asamblea Nacional, o imponer obligaciones a la voluntad democrática del pueblo de Quebec para determinar su propio futuro».

Si atendemos de modo genérico a otros casos más cercanos como el vasco o el catalán podemos observar que las líneas paralelas no se cruzan, y, por lo tanto, los deseables puntos de encuentro no se producen.

En cuanto a la comunidad autónoma vasca, el antecedente más inmediato en España es el proceso de reforma territorial iniciado por el lehendakari Ibarretxe en 2003. Esta Propuesta independentista del Pueblo Vasco se fundamentaba en el derecho de autodeterminación de los pueblos, reconocido en el Pacto Internacional de Derechos Civiles y Políticos y en el Pacto Internacional de Derechos Económicos, Sociales y Culturales.

El denominado Plan Ibarretxe de 2003, definía al Pueblo Vasco o Euskal Herria como «un Pueblo con identidad propia en el conjunto de los pueblos de Europa, depositario de un patrimonio histórico, social y cultural singular que se asienta geográficamente en siete territorios actualmente articulados en tres ámbitos jurídico-políticos diferentes ubicados en dos estados».

En referencia a la resolución de los conflictos territoriales que pudieran plantearse entre el Estado y el País Vasco, el artículo 16 del Plan preveía la creación de un Tribunal de Conflictos Euskadi-Estado. Asimismo, se establecían una serie de medidas especiales de ordenación jurídica y procesal del Tribunal Constitucional en relación con la Comunidad de Euskadi. Se planteaba la creación de una nueva Sala Especial del Tribunal Constitucional, que se constituía en el Tribunal de Conflictos Euskadi-Estado, y conocería de los procedimientos de declaración de inconstitucionalidad y de los conflictos constitucionales que se pudieran suscitar en relación con las Instituciones y poderes de la Comunidad de Euskadi. Asimismo, se establecía un nuevo procedimiento de conflicto de competencias negativo ante el Tribunal Constitucional, que tendría como actor al Gobierno Vasco y como órgano requerido al Gobierno del Estado, por declararse éste incompetente para ejercitar las atribuciones que le confieren la Constitución o las Leyes en relación a la Comunidad de Euskadi. La Sentencia del Tribunal podrá, o bien declarar la improcedencia del requerimiento, o bien declarar su procedencia, estableciendo en tal caso un plazo dentro del cual se dejará ejercitar la atribución requerida.

Por otro lado, uno de los conflictos territoriales recurrente y dominante en España en los últimos años, y especialmente tras la última reforma estatutaria, nos remite a Cataluña. El prisma con el que lo referenciaremos será el de los instrumentos pre y para judiciales que se presentan en el conflicto. Una somera revisión del mismo nos lleva a la creación, el 12 de febrero de 2013, del Consell assessor per a Transició Nacional, formado por trece juristas y otras personas que apoyan el derecho a decidir, el cual publicó un análisis relativo a la consulta sobre el futuro político de Cataluña, en cuyos postulados reconocen su legitimidad histórica para constituirse como Nación. Defienden que «las referencias históricas personalizan el caso de Catalunya como una de las colectividades nacionales diferenciadas más antiguas de Europa».

${ }^{36}$ Resulta interesante verificar un seguimiento del iter de este precepto. Así, el Proyecto de Ley de diciembre de 1999 sostenía que «el pueblo de Quebec solo tiene el derecho a decidir el régimen político y el status legal de Québec». El giro eufemístico que se ha imprimido a este segundo artículo se evidencia por la sustitución del adverbio «solo», por «libremente», obvia un enfrentamiento con el dictamen del Tribunal Supremo de agosto de 1998. 
Asimismo, el Consell sostiene que la tradición política de Catalunya ha sido muy predominantemente de carácter dialogante y pactista, fruto del equilibrio histórico en que se fundamentan sus instituciones desde si inicio.

Junto a esa posición que sostiene el Consell, podemos referirnos a aquella sostenida desde un sector doctrinal, que defiende la existencia de un déficit de acomodación (Barceló i Serramalera, et al, 2015: 20) de Cataluña dentro del Estado español, basado, por un lado, en la demanda de mayor reconocimiento de esa comunidad como sujeto político, con voluntad propia, en el seno del Estado, superando de este modo un posible fallo de reconocimiento, y por otro en la demanda de mayor autonomía y capacidad política en la toma de decisiones como sujeto político autónomo y, de manera compartida, en el conjunto del Estado. Asimismo, el contexto político marcado por el pronunciamiento del Tribunal Constitucional que supuso la STC 31/2010, conforme a la cual se modificaba en sus principales contenidos la reforma del Estatuto de autonomía de Cataluña de 2006 supone el caldo de cultivo en el que surgen con fuerza las demandas reivindicativas de una Cataluña independiente.

Desde un sector de la doctrina, se considera que el contexto político que se forma tras ella dirigido por el Estado central, con la mayoría absoluta del PP en 2011, permitió llevar a cabo tres actuaciones (Barceló i Serramalera, et al, 2015:152): una ofensiva judicial y legal contra la lengua catalana y, en particular, contra el modelo lingüístico vigente; una recentralización de competencias que afecta a todos los ámbitos y servicios públicos y la no obtención del pacto fiscal, que se traduciría en el agravamiento del déficit fiscal de Cataluña, reduciendo las inversiones públicas del Estado, neutralizando los intentos del gobierno catalán de crear nuevos tributos, e imponiendo duros objetivos de déficit público.

Cabe concluir, que el derecho a decidir en Cataluña se ha planteado fundamentalmente en clave emocional, más como expresión de anhelos poco verosímiles que como proyecto pragmáticamente elaborado.

\subsection{Definición, vías de resolución y sus características}

En la esencia del Estado compuesto, reside, pues, el conflicto, y al mismo tiempo la instauración de vías o de mecanismos para la solución de esas controversias territoriales (Aparicio, et al, 2012:555).

De las vías previstas en nuestro ordenamiento jurídico, la negocial es la que ahora nos interesa.

La vía negocial, caracterizada por su no constitucionalización y no obligatoriedad ha supuesto la generalización en el uso de la vía jurisdiccional como mecanismo de resolución de conflictos territoriales. En la citada vía las partes, de forma directa o el seno de una institución, generalmente la cámara legislativa territorial, intentan una solución pactada del conflicto.

En este sentido, debemos aludir a la Ley Orgánica 2/1979, de 3 de octubre, del Tribunal Constitucional, que regula dos mecanismos estables de negociación: el requerimiento previo de incompetencia y el período negociador. Requerimiento previo de incompetencia: Se trata de un procedimiento previo a la formalización del conflicto de competencia formulado contra las disposiciones, las resoluciones y los actos emanados de los órganos del Estado o de los órganos de las Comunidades Autónomas. Este procedimiento, de carácter potestativo para el Estado y obligatorio para las Comunidades Autónomas, tiene como objetivo primordial el intentar una solución amistosa de las partes. Si bien, el plazo para formalizar directamente el conflicto positivo de competencia o hacer uso del requerimiento de incompetencia es de dos meses desde la publicación o comunicación del acto o disposición viciado de incompetencia. En el caso de que la Comunidad Autónoma requerida no atienda el requerimiento de incompetencia en el plazo de un mes, el Gobierno dispone del plazo de un mes, a contar desde la notificación del rechazo del requerimiento o desde el término del plazo del que dispone la Comunidad Autónoma requerida para contestarlo, para plantear el conflicto ante el Tribunal Constitucional, certificando el cumplimiento infructuoso del requerimiento de incompetencia y alegando los fundamentos jurídicos en los que sustenta su pretensión.

Por su parte, la segunda de las vías negociales, el período negociador, fue introducido por la Ley Orgánica 1/2000, de 7 de enero, de modificación de la Ley Orgánica 2/1979, de 3 de octubre, del Tribunal Constitucional. En la propia Exposición de Motivos, el legislador aboga por «intensificar los lazos de colaboración y entendimiento entre el Estado y las Comunidades Autónomas, en el intento de buscar entre todos, dentro del respectivo e indispensable marco competencial, métodos flexibles y adecuados de convergencia que disminuyan la conflictividad».

Este mecanismo consiste en la comunicación al Tribunal Constitucional de los acuerdos adoptados en las Comisiones Bilaterales de Cooperación, con el objetivo de evitar la interposición de un recurso de inconstitucionalidad, ampliándose el plazo de interposición del mismo, con el fin de que pueda llegarse a un acuerdo que lo evite. 
En síntesis, si la eficacia de este procedimiento fijado en el art. 33. 2 de la LOTC ha sido encomiable (Roig Molés 2016: 5-7) hay conflictos que quedan al margen del mismo. Cuando el conflicto trasciende una ley, es decir, se superpone a todas ellas y parece enquistar el proceso, este mecanismo es insuficiente. En segundo lugar, la necesidad de habilitar un proceso más abierto de resolución de conflictos permitiría incorporar a Comunidades Autónomas no vinculadas a hechos diferenciales, potenciando una mejor calidad de la percepción de la autonomía por parte de los territorios y de los ciudadanos. En tercer lugar, la importancia de combinar estructuras bilaterales con otras técnicas, reforzaría las primeras. Finalmente, la apertura del momento. La necesidad de apostar por fórmulas negociadoras no vinculadas a un período de nueve meses previo a la interposición de un recurso de inconstitucionalidad relajaría ese instrumento y ampliaría las posibilidades del mismo.

En consecuencia, es preciso habilitar cauces alternativos de negociación a los conflictos territoriales, con un referente de participación más amplio, con un menor rigor sincrónico y con la búsqueda de resultados, menos técnicos, pero más productivos a largo alcance y plazo.

\section{REFLEXIONES FINALES}

La globalización ha supuesto el empoderamiento de las esferas supraestatales y la pérdida paulatina de la capacidad efectiva para imponer límites materiales al ejercicio de un poder que ya no es sólo estatal, lo que supone el surgimiento del concepto de soberanía jurídica internacional/global.

La cooperación entre el Estado y los organismos infra y supraestatales se constituye como un medio imprescindible para la resolución de conflictos territoriales.

Frente al ámbito interno estatal, en el ámbito global prevalece el uso de los sistemas diplomáticos previamente a los jurisdiccionales y dentro de los diplomáticos aquellos en los cuales intervienen directamente los Estados implicados.

En la esfera internacional se viene produciendo un incremento en la utilización de varios sistemas: la negociación y/o la mediación si nos encontramos ante un conflicto de los que hemos denominado políticos, y el arbitraje si nos hallamos ante conflictos jurídicos.

Una vía complementaria apunta a la potenciación de la Convención constitucional como reunión o agrupación de ciudadanos y sus representantes, avalados por precedentes organizativos similares y determinados por el compromiso político de gobernabilidad basado en el poder discrecional del ejecutivo, que actúan con la finalidad de dotar de un suplemento al contenido normativo de la Constitución, a otra norma, o a una situación conflictiva política y territorialmente, a los efectos de potenciar su flexibilidad, adoptándolas a las circunstancias cambiantes de la vida, a unas nuevas necesidades es una posibilidad a explorar en nuestro país. En el caso español podríamos optar por convenciones estatutarias de participación ciudadana.

En nuestro ordenamiento jurídico se han previsto tres vías de resolución de conflictos territoriales: la vía negocial, la vía jurisdiccional y la vía coactiva, de ejecución forzosa, cumplimiento forzoso o coerción estatal.

La vía jurisdiccional se alza como principal medio de resolución de los conflictos territoriales en el ordenamiento interno español. Pero su dificultad para afrontar conflictos más amplios y enquistados obliga a explorar otras alternativas.

El procedimiento fijado en el art. 33. 2 de la LOTC ha sido encomiable, más hay conflictos que quedan al margen del mismo. Cuando el conflicto trasciende una ley, es decir, se superpone a todas ellas y parece enquistar el proceso, este mecanismo es insuficiente. En segundo lugar, la necesidad de habilitar un proceso más abierto de resolución de conflictos permitiría incorporar a Comunidades Autónomas no vinculadas a hechos diferenciales, potenciando una mejor calidad de la percepción de la autonomía por parte de los territorios y de los ciudadanos. En tercer lugar, la importancia de combinar estructuras bilaterales con otras técnicas, reforzaría las primeras. Finalmente, la apertura del momento. La necesidad de apostar por fórmulas negociadoras no vinculadas a un período de nueve meses previo a la interposición de un recurso de inconstitucionalidad relajaría ese instrumento y ampliaría las posibilidades del mismo.

En síntesis, la apelación a los esfuerzos de todos los sujetos afectados a no cejar en buscar alternativas, vías complementarias y recursos de origen difuso ha de ser un reto a la imaginación y al trabajo, en este caso el académico, pero fundamentalmente al político y al administrativo.

\section{REFERENCIAS BIBLIOGRÁFICAS}

ANTUNES, N. S. M. (2008), "The 1999 Eritrea-Yemen Maritime Delimitation Award And The Development of International Law", International and Comparative Law Quarterly, 50(2), DOI: 10.1093/iclq/50.2.299. En línea: $<$ https://www.cambridge.org> (consulta: 6 octubre 2016). 
APARICIO PÉREZ, M. A. y BARCELÓ Y SERRAMALERA, M. (2012), Manual de Derecho Constitucional, Barcelona: Atelier.

BARCELÓ I SERRAMALERA, M.; CORRETJA, M.; GONZÁLEZ BONDIA, A.; LÓPEZ, J.; VILAJOSANA, J. M. (2015), El derecho a decidir. Teoría y práctica de un nuevo derecho, Barcelona: Atelier.

BERCOVITCH, J. (1989). Mediation in International Disputes en Kenneth Kressel and Dean G. Pruitt (eds.). Mediation Research, San Francisco: Jossey Bass.

BERCOVITCH, J. y HOUSTON, A. (2000), Why Do They Do It Like This? An Analysis of the Factors Influencing Mediation Behavior in International Conflicts Journal of Conflict Resolution. April, 44: 170-202. En línea: <http://jcr. sagepub.com > (consulta: 6 octubre 2016).

BERCOVITCH, J. y LEE, S.-M. Mediating international conflicts: examining the effectiveness of directive strategies in The International Journal of Peace Studies. En línea: <http://www.gmu.edu> (consulta: 6 octubre 2016).

BERLINGUER, A. (2013): "Hacia un modelo europeo de mediación", Revista Aranzadi Doctrinal, 5:195-203.

GARCÍA GÉRBOLES, L. y MUESMANN TORRES, M. (2010). "El entronque histórico-jurídico del concepto de la mediación desde el derecho romano hasta la actualidad", La mediación: presente, pasado y futuro de una institución jurídica. Oleiros (La Coruña), Netbiblo.

GOBBI, J., (2010). El Concepto de conflicto y los medios de Solución de Controversias en el Derecho Internacional. En línea: <www.caei.com.ar> (consulta: 6 octubre 2016).

HELD, D., (1997). La democracia y el orden global: del estado moderno al gobierno cosmopolita. Barcelona: Paidós.

LÓPEZ-BARAJAS PEREA, I. (2012): "La mediación civil y mercantil y sus garantías: un paso más en la creación de un espacio judicial europeo", Revista General de Derecho Europeo, 27.

LÓPEZ MARTíN, A. G. (2013). "El arreglo de las controversias territoriales por la Corte Internacional de Justicia. Una aproximación a sus líneas directrices", en REDUR II, diciembre, págs. 55-72.

MARQUÉS CEBOLA, C. (2013). La mediación. Madrid: Marcial Pons.

MARTÍ MINGARRO, L. (2013): "La mediación civil y mercantil en la nueva Ley 5/1012, de 6 de julio", Revista Jurídica de Castilla de León, 29.

MITJANS, E., CASTELLÀ, J. M. (2001). Canadá. Introducción al sistema político y jurídico, Barcelona: Canadiana.

MUHIAR, H., (2015). Derecho internacional público: La solución pacífica de las controversias internacionales. En línea: $<$ http://www.gloobal.net> (consulta: 6 octubre 2016).

MUNNÉ CATARINA, F. y VIDAL TEIXIDÓ, A., (2013). La mediación: resolución pacífica de conflictos, régimen jurídico y eficacia procesal. Madrid: La Ley.

OLIVER ARAUJO, J., (2014). El futuro territorial español ¿Centralización, autonomía, federalismo, confederación o secesión?, Valencia: Tirant lo Blanch.

PETERS, A., AZNAR GÓMEZ, M. J. y GUTIÉRREZ GUTIÉRREZ, I., (2010). La constitucionalización de la comunidad internacional. Valencia: Tirant lo Blanch.

RAMÍREZ CLEVES, J. A. Transformaciones del constitucionalismo en el contexto de la globalización. En línea: <http:// www.alfonsozambrano.com/nueva_doctrina/07082011/ndptransformaciones_constitucionalismo.pdf> (consulta: 6 octubre 2016).

ROIG MOLÉS, E. (2015). "Contenido y eficacia de los acuerdos de las comisiones bilaterales en el procedimiento del artículo 33.2 LOTC", Informe comunidades autónomas, 2015, Pp. 39-70.

SÁEZ HIDALGO I., DORREGO DE CARLOS, A. Coord. (2013). Arbitraje y mediación: problemas actuales y oportunidades. Valladolid: Lex Nova.

SEIJAS VILLADANGOS, E., (2012). "Irlanda: reforma constitucional versus convención constitucional". En Teoría y Realidad Constitucional, núm. 30, págs. 411-432.

SEIJAS VILLADANGOS, E. (2001). "El federalismo canadiense ante la curiosidad de un jurista español", en PAU I VALL, F. El futuro del Estado Autonómico, Pamplona, Aranzadi, págs. 227-251.

STOLLEIS, M., PAULUS, A., GUTIÉRREZ GUTIÉRREZ, I., (2013). El derecho constitucional de la globalización. Madrid: Fundación Coloquio Jurídico Europeo.

TEWBNER, G., SASSEN, S., KRASNER, S., D., SALDIVIA, L., (2010). Estado, soberanía y globalización. Bogotá: Siglo del Hombre.

VEGA, P., (1985). La reforma constitucional y la problemática del poder constituyente. Madrid: Tecnos.

XIOL RíOS, J. A. (2013). El diálogo entre Tribunales. Tribunal Constitucional y diálogo entre tribunales: XVIII Jornadas de la Asociación de Letrados del Tribunal Constitucional, Madrid, Centro de Estudios Políticos y Constitucionales.

\section{REFERENCIAS DOCUMENTALES}

Carta de Naciones Unidas. En línea: <http://www.un.org> (consulta: 6 octubre 2016).

Convención (IV) de La Haya, de 18 de octubre de 1907 relativa a las leyes y costumbres de la guerra terrestre. En línea: <http://portal.unesco.org/> (consulta: 6 octubre 2016). 
Convención de Viena sobre Derecho de los Tratados, de 23 de mayo de 1969, En línea: <http://www.derechos.org> (consulta: 6 octubre 2016).

Declaración de principios entre España, Marruecos y Mauritania sobre el Sahara occidental, celebrada en Madrid, a 14 de noviembre de 1975. En línea: <http://peacemaker.un.org/mauritania-morocco-spain-principles75> (consulta: 6 octubre 2016).

Resolución 2625 (XXV) de la Asamblea General de Naciones Unidas, de 24 de octubre de 1970, que contiene la Declaración relativa a los Principios de Derecho Internacional referentes a las relaciones de amistad y a la cooperación entre los Estados de conformidad con la Carta de las Naciones Unidas. En línea: <http://ocw.um.es> (consulta: 6 octubre 2016).

Resolución 37/10 de la Asamblea General de las Naciones Unidas. Declaración de Manila sobre el Arreglo Pacífico de Controversias Internacionales.

Resolución 46/59 de la Asamblea General Declaración sobre la determinación de los hechos por las Naciones Unidas en la esfera del mantenimiento de la paz y la seguridad internacionales. En línea: http://legal.un.org das, Preámbulo, párrafo 1.․ En línea: <http://www.un.org> (consulta: 6 octubre 2016).

Tratado de Jay, firmado en Londres el 19 de noviembre de1794 entre USA y Gran Bretaña. En linea: <https://memory. loc.gov> (consulta: 6 octubre 2016).

Tribunal Permanente de Justicia Internacional asunto Mavrommatis (CPJI Serie A, núm. 2, 1924) en Palestina (Grecia c. Reino Unido), sentencia del 30 de agosto de 1924. En línea: <www.icj-cij.org> (consulta: 6 octubre 2016).

Código de Conducta Europea para mediadores. En línea: <http://ec.europa.eu/civiljustice/adr/adr_ec_code_conduct_ es.pdf> (consulta: 6 octubre 2016).

Directiva 2008/52/CE del Parlamento Europeo y del Consejo de 21 de mayo de 2008 sobre ciertos aspectos de la mediación en asuntos civiles y mercantiles (DOUEL núm. 136 de 24 de mayo de 2008). En línea: <https://www. boe.es/doue/2008/136/L00003-00008.pdf> (consulta: 6 octubre 2016).

Resolución del Parlamento Europeo, de 13 de septiembre de 2011, sobre la aplicación de la Directiva sobre la mediación en los Estados miembros, su impacto en la mediación y su aceptación por los Tribunales. En línea: <http://www.europarl.europa.eu/sides/getDoc.do?pubRef=-//EP//TEXT+TA+P7-TA-2011-0361+0+DOC+XML+V0// ES> (consulta: 6 octubre 2016).

Ley 5/2012, de 6 de julio de mediación en asuntos civiles y mercantiles (BOE núm. 162, de 7 de julio de 2012). En línea: <https://www.boe.es/diario_boe/txt.php?id=BOE-A-2012-9112> (consulta: 6 octubre 2016).

Real Decreto 980/2013 por el que se desarrollan determinados aspectos de la Ley 5/2012, de mediación en asuntos civiles y mercantiles (BOE núm. 310, de 27 de diciembre de 2013). En línea: <https://www.boe.es/diario_boe/txt. php?id=BOE-A-2013-13647> (consulta: 6 octubre 2016).

Ley $1 / 2011$ de 28 de marzo de mediación de la Comunidad Autónoma de Cantabria (BOE núm. 99, de 26 de abril de 2011). En línea: <http://www.boe.es/buscar/doc.php?id=BOE-A-2011-7406> (consulta: 6 octubre 2016). 